\title{
The Biological Role of the Collagen Alpha-3
Chain and Its Cleaved C5 Domain Fragment Endotrophin in Cancer
}

This article was published in the following Dove Press journal: OncoTargets and Therapy

\section{Jingya Wang \\ Wensheng Pan}

Department of Gastroenterology, The Second Affiliated Hospital of Zhejiang University School of Medicine, Hangzhou, Zhejiang, People's Republic of China
Correspondence: Wensheng Pan Department of Gastroenterology, The Second Affiliated Hospital of Zhejiang University School of Medicine, Hangzhou 310009 , Zhejiang, People's Republic of China

Tel +86- $136066225 \mid 2$

Fax +86-57I-8589-3860

Email pan2010@zju.edu.cn

\begin{abstract}
The collagen alpha-3 (VI) chain encoded by the gene COL6A3 is one of the 3 subunits of collagen VI which is a microfibrillar component of the extracellular matrix and is essential for the stable assembly process of collagen VI. The collagen alpha-3 (VI) chain and the cleaved C5 domain fragment, called endotrophin, are highly expressed in a variety of cancers and play a crucial role in cancer progression. The biological functions of endotrophin in tumors can be driven by adipocytes. Studies have demonstrated that endotrophin can directly affect the malignancy of cancer cells through TGF- $\beta$-dependent mechanisms, inducing epithelialmesenchymal transition and fibrosis of the tumor microenvironment. In addition, endotrophin can also recruit macrophages and endothelial cells through chemotaxis to regulate the tumor microenvironment and ultimately promote tumor inflammation and angiogenesis. Furthermore, COL6A3 and endotrophin serve as novel diagnostic and prognostic biomarkers in cancer and contribute to clinical therapeutic applications in the future. In summary, in this review, we discuss the importance of the collagen alpha-3 (VI) chain and endotrophin in cancer progression, the future clinical applications of endotrophin and the remaining challenges in this field.
\end{abstract}

Keywords: COL6A3, collagen VI, endotrophin, chemoresistance, cancer

\section{Introduction}

Collagen VI is an essential part of the extracellular matrix (ECM) and a key component in the microenvironment of several tumors. ${ }^{1,2}$ A deregulated and disorganized ECM contributes to the malignant development of tumors, causing tumor-associated angiogenesis and inflammation facilitated by the deregulated behavior of stromal cells, eventually leading to the formation of a microenvironment that promotes cancer. ${ }^{1}$ There are three major subunits of collagen VI: alpha-1 (VI), alpha-2 (VI), and alpha-3 (VI) chains, which are encoded by the genes COL6A1, COL6A2, and COL6A3, respectively. ${ }^{3-5}$ Compared with the $140-150 \mathrm{kDa}$ (1000 amino acids in length) alpha-1 (VI) and alpha-2 (VI) chains, the alpha-3 (VI) chain is approximately 3 times larger in weight $(250-300 \mathrm{kDa})$ with multiple alternatively spliced variants ranging from 2500 to 3100 amino acids. ${ }^{6-10}$ The subunits of collagen VI have a similar molecular structure: a short triple-helical domain (335-336 amino acids collagenous domain) and two large globule-like N-terminal and C-terminal noncollagenous domains composed of 200 repeating amino acids motifs similar to the von Willebrand factor type A (vWF-A) modules. The alpha-1 (VI), alpha-2 (VI) and alpha-3 (VI) chains all have one N-terminal (N1) and two C-terminal (C1 and C2) 
vWFA modules. However, in the collagen alpha-3 (VI) chain there are 9 additional vWF-A modules in the $\mathrm{N}$ terminus (N2-N10) and 3 special domains in the $\mathrm{C}$ terminus (C3-C5) — one unique domain (C3), one fibronectin type III domain, and one Kunitz domain (C5). ${ }^{7,10}$ (Figure 1)

Recently, 3 novel subunits of collagen VI are revealed: alpha-4 (VI), alpha-5 (VI), and alpha-6 (VI) chains encoded by the COL6A4, COL6A5 and COL6A6 genes. These 3 novel chains structurally resemble the alpha-3 (VI) chain with a short triple-helical domain, $7 \mathrm{vWF}-\mathrm{A}$ domains in the $\mathrm{N}$ terminus, and 2 vWF-A domains and a unique domain in the $\mathrm{C}$ terminus. Additionally, the alpha-4 (VI) chain contains a Kunitz domain in the $\mathrm{C}$ terminus, and the alpha-5 (VI) chain carries another vWF-A domain and a unique domain. However, in humans, the COL6A4 gene is disrupted by a chromosome break to create two pseudogenes. (Figure 1) The generation of these new collagen VI alpha-chains may be due to a gene duplication of their common ancestor COL6A3, and then these new alpha-chain genes were additionally duplicated. $^{11-14}$ (Figure 1)

The assembly of collagen VI is a complicated process. Earlier studies have shown that collagen VI is firstly assembled into a triple helix monomer by the alpha-1 (VI), alpha-2 (VI) and alpha-3 (VI) chains in a stoichiometric ratio of 1: 1: 1 . Then the triple helix monomers are staggered into anti-parallel dimers bonded by disulfide bonds, and the antiparallel dimers are also aligned through disulfide bonds to form tetramer. Further, these tetramers are secreted to the extracellular matrix and form beaded microfibrils in a way of end-to-end connection of overlapped N-terminal globular domains through non-covalent bonds. ${ }^{15-19}$ The maturation of collagen VI microfibrils (fibril processing) in the extracellular matrix is a continuous process that starts immediately when tetramers are secreted, ${ }^{20}$ and requires proteolytic process involving the removal of the $\mathrm{C}$-terminus of the collagen alpha-3 (VI) chain (For example, the C-5 or the C2-C5 domains cleavage fragments) after microfibril assembly. $^{5,12,20}$ (Figure 2) The discovery of new collagen VI

$\begin{array}{cccc}\text { Human gene } & \text { Gene position } & \text { Chain } & \text { Size(kDa) } \\ \text { COL6A1 } & 21 \mathrm{q} 22.3 & \alpha 1(\mathrm{VI}) & 130-150 \\ \text { COL6A2 } & 21 \mathrm{q} 22.3 & \alpha 2(\mathrm{VI}) & 130-150 \\ \text { COL6A3 } & 2 \mathrm{q} 37 & \alpha 3(\mathrm{VI}) & 250-300 \\ & & & \\ \text { COL6A4 } & 3 \mathrm{q} 21 & \alpha 4(\mathrm{VI}) & 220-300 \\ \text { COL6A5 } & 3 \mathrm{q} 21 & \alpha 5(\mathrm{VI}) & 220-300 \\ \text { COL6A6 } & 3 q 21 & \alpha 6(\mathrm{VI}) & 220-300\end{array}$

Triple Helical domain

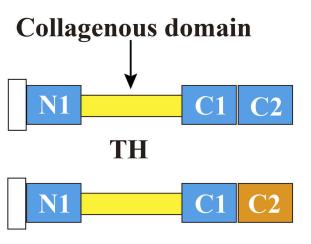

TH \begin{tabular}{|l|l|l|l|l|l|l|l|l|l|} 
N10 & N9 & N8 & N7 & N6 & N5 & N4 & N3 & N2 & N1 \\
\hline
\end{tabular} $\begin{array}{llllllllll}\text { E3 } & \text { E4 } & \text { E5 } & \text { E6 } & \text { E7 } & \text { E8 } & \text { E9 } & \text { E10 } & \text { E11 }\end{array}$

TH

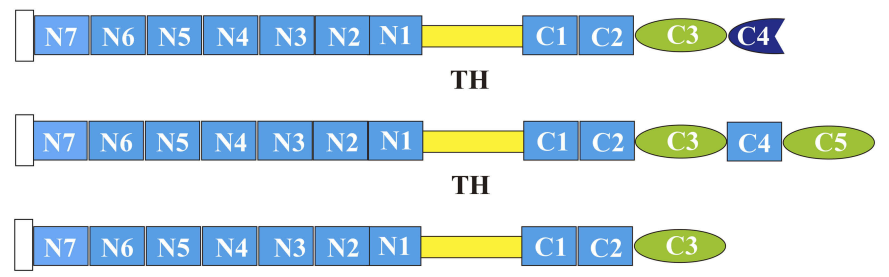

TH

Unique domain

Signal peptide

Figure I Schematic diagram of the subunits of collagen VI. All the 6 chains and their encoding genes are presented. The molecular structures of collagen VI subunits are similar: a short collagenous triple-helical domain and three von Willebrand factor type A (vWF-A) domains ( $\mathrm{NI}, \mathrm{Cl}$, and $\mathrm{C2}$ ). Nine additional vWF-A domains are found in the N-terminal domain ( $2-\mathrm{N} 10$ ) and 3 special domains are found in the C-terminal domain (C3-C5) in the collagen alpha-3 (VI) chain. The area marked by arrows shows the collagenous domain and the cleaved C5 domain fragment endotrophin. In humans, the COL6A4 gene is disrupted by a chromosome break to create two pseudogenes. In addition, the N2-N10 vWF-A domains are each encoded by a single exon accordingly from exon II to exon 3 (EII-E3), and the domains undergo alternative splicing are marked orange. Due to the alternative splicing of COL6A3 at the pre-mRNA level, the N3, N5, N7, N9 and NI 0 vWF-A domains of the collagen alpha-3 (VI) chain are either present or absent in the final chain. The tumor-specific alternative splicing of exons 6, 4, and 3 (E6, E4, and E3) are also showed in the Figure in Red marks. This figure was modified with permission from Cescon M, Gattazzo F, Chen P, Bonaldo P. Collagen VI at a glance. J Cell Sci. 2015;I28(19):3525-353I. doi:10.1242/jcs. 169748. Copyright 20I5, The Company of Biologists Ltd. ${ }^{100}$

Abbreviations: TH, triple helical; vWF-A, von Willebrand factor type A; E3, exon 3; E4, exon 4; E5, exon 5; E6, exon 6; E7, exon 7; E8, exon 8; E9, exon 9; EI0, exon I0; EII, exon II. 
Intracellular

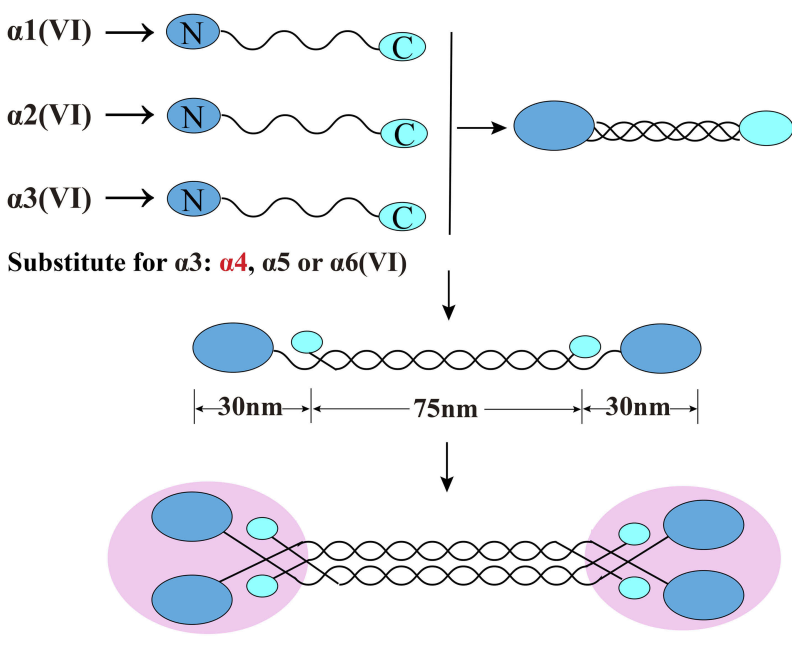

Extracellular

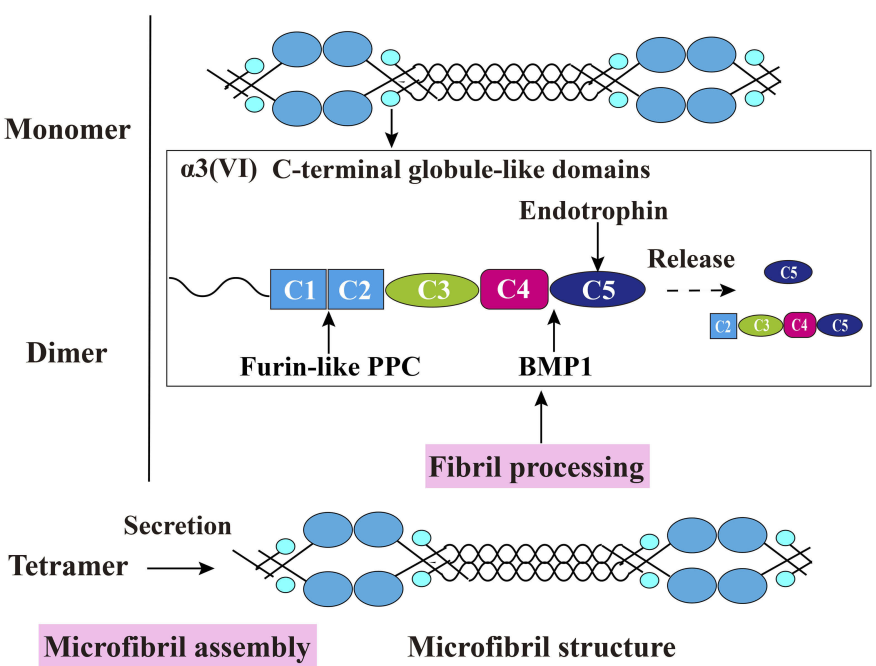

N-terminal globule-like domains

Fibronectin type III domain
C-terminal globule-like domains

Kunitz-like domain
Globule-like domains $\frown$ Triple Helical domain

vWF-A domain

Unique domain

Figure 2 Schematic diagram of collagen $\mathrm{VI}$ assembly process. Collagen $\mathrm{VI}$ is firstly assembled into a triple helix monomer by the alpha-I (VI), alpha-2 (VI) and alpha-3 (VI) chains in a stoichiometric ratio of $\mathrm{I}: \mathrm{I}: \mathrm{I}$. Then the triple helix monomers are staggered into anti-parallel dimers bonded by disulfide bonds, and the anti-parallel dimers are also aligned through disulfide bonds to form tetramer. Further, these tetramers are secreted to the extracellular matrix and form beaded microfibrils in a way of end-to-end connection of overlapped $\mathrm{N}$-terminal globular domains through non-covalent bonds. The maturation of collagen VI microfibrils (fibril processing) in the extracellular matrix is a continuous process that starts immediately when tetramers are secreted, and requires proteolytic process involving the removal of the $\mathrm{C}$-terminal domains of the collagen alpha-3 (VI) chain (for example, the $\mathrm{C} 5$ or the C2-C5 domains cleavage fragments) after microfibril assembly. The alpha-5 (VI) and alpha-6 (VI) chains can be substituted for alpha-3 (VI) chains in human. Furin-like PPC and BMP-I are two proteins involving the endotrophin-containing fragments releasing process, and the cleavage sites are between the $\mathrm{C} 4$ and $\mathrm{C} 5$ domains as well as the the $\mathrm{Cl}$ and $\mathrm{C} 2$ domains. This figure was modified with permission from Furthmayr H, Wiedemann H, Timpl R, Odermatt E, Engel J. Electron-microscopical approach to a structural model of intima collagen. Biochem J. 1983;2I I (2):303-31 I. doi: 10.1042/bj2 I 10303. Copyright 1983, Portland Press, Ltd. ${ }^{101}$

Abbreviations: vWF-A, von Willebrand factor type A; Furin-like PPC, furin-like proprotein convertase; BMP-I, bone morphogenetic protein I.

alpha-chains in recent years has also added the complexity of the assembly process. Studies have shown that the new alphachains have the same collagenous domain (triple helical domain) size as the collagen alpha-3 (VI) chain and the mutation of COL6A3 will not affect the normal expression of alpha5 and alpha- 6 chains, which indicate that they could directly replace the alpha-3 chain and may form $\alpha 1 \alpha 2 \alpha 5$ or $\alpha 1 \alpha 2 \alpha 6$ heterotrimers in human. ${ }^{14,21,22}$ (Figure 2) Nevertheless, there is currently no direct evidence that these new chains can be assembled with alpha-1 and alpha-2 chains. In addition to these basic descriptions of the assembly of the tetramers and microfibrils, the detailed process of collagen VI subunits protein domains interaction involved into the assembly is still unknown. What is clear is that the collagen alpha-3 (VI) chain plays a central role in collagen VI assembly. The normal synthesis of alpha-3 (VI) is an essential step in the accumulation of stable collagen VI molecular in the ECM, while alpha-1 (VI) chain and alpha-2 (VI) chain cannot form stable collagen VI. ${ }^{23}$ These results were proved in vitro collagen alpha-3 (VI) chain lacked osteosarcoma cell line SaOS-2. In the absence of alpha-3 (VI) chain, the alpha-1 (VI) and alpha-2 (VI) chains were produced with non-helical structures and mostly remained in cell and degraded. ${ }^{23}$ Moreover, data suggested that the C-terminal globular domains of alpha-3 (VI) chain played a fundamental role in chain selection and initiation of collagen VI helix formation, ${ }^{24,25}$ as the C2-C5 vWF-A domains were not required for collagen VI monomer, dimer or tetramer molecular assembly ${ }^{5}$ which suggested that the $\mathrm{C} 1$ vWF-A domain got involved into the important chain selection interactions. Expect for the tetramer molecular assembly, experiments have also confirmed that the alpha-3 (VI) C5 domain played a crucial role in the assembly of collagen VI microfibrils. ${ }^{5}$ The tetramer contains C5 domain truncated alpha-3 (VI) chain cannot effectively associate end-to-end connection to form collagen VI microfibrils compared with the tetramer contains the control alpha-3 (VI) N6-C5 chain. Therefore in the full collagen VI molecular, the $\mathrm{C} 5$ domain only presents in the cytoplasm, and the immediate pericellular matrix where the microfibrils are assembled, but is immediately cleaved and not presented in the mature collagen VI- 
containing matrix after microfibril assembly. ${ }^{12}$ In respect of the N-terminal domains, even though the N7-N10 vWF-A domains of the alpha-3 (VI) chain are not required for collagen VI molecular assembly, ${ }^{23}$ the N5 domain also plays an important role in the assembly of collagen VI microfibrils. ${ }^{24}$ More importantly, the N-terminal domains can extend from the spherical beaded region, so it has a potential interaction surface with other cell matrix molecules. ${ }^{25}$

Previous studies have demonstrated that collagen VI is expressed in a variety of human tissues and distributed among connective tissues such as skin, blood vessels, and adipose tissue; ${ }^{10,26}$ nervous tissues, ${ }^{27,28}$ and muscle tissues. ${ }^{10}$ In the extracellular matrix environment, the collagen VI network anchors large interstitial structures such as blood vessels, nerves, and collagen fibers into the surrounding connective tissues, thereby providing physical support for cells. ${ }^{26}$ In the cancer microenvironment, collagen VI can take part in the regulation of cancer apoptosis, $^{29}$ autophagy, ${ }^{30}$ fibrosis, angiogenesis, and inflammation. ${ }^{31,32}$ Collagen VI and its subunits show high expression levels in different type of tumors. ${ }^{2}$ However, there are very few literatures describing the differential expression and the mutual influence of these subunits in tumors which are crucial for understanding how these subunits can affect cancer progression. In recent years, an increasing number of studies have demonstrated that the collagen alpha-3 (VI) chain plays an important role in tumorigenesis. In particular, the C-terminal globular domains of the alpha-3 (VI) chain undergoes proteolytic process in a time and tissue specific manner to produce C5 domain-containing cleavage fragments with signal transduction ability. ${ }^{14,21,22,33}$ Nevertheless, current knowledge of the nature of these $\mathrm{C} 5$ domain-containing fragments, the cleavage sites, and the proteases involved are very limited. ${ }^{20}$ The C5 Kunitz-like domain with the name "endotrophin" is the major mediator of collagen VImediated tumor effects ${ }^{31,34-36}$ that is cleaved and not present in the mature collagen VI-containing matrix after collagen VI microfibril assembly. ${ }^{12,37}$ Therefore, compared with the remainder of the collagen alpha-3 (VI) chain, endotrophin serves an important role in collagen VI related tumor progression. Furthermore, as the collagen $\alpha 3$ (VI) chain plays a crucial role in stable collagen VI structure assembly. It is unclear whether the effect of collagen $\alpha 3$ (IV) chain on tumor progression is due to the loss of collagen VI structural function, or the loss of signal transduction function or both. For these reasons, it is important to summarize the underlying mechanism of the collagen alpha-3 (VI) chain and endotrophin in cancer.

In this review, we provide a detailed summary of the current knowledge on the procarcinogenic function of the collagen alpha-3 (VI) chain and endotrophin in tumor progression, their roles as biomarkers and in chemotherapy resistance, and future clinical applications and potential problems that remain in this field.

\section{The Expression of the Collagen Alpha-3 (VI) Chain in Cancer}

The collagen alpha-3 (VI) chain is widely expressed in various cancer cell lines and tissues.(Table 1). Even though the cells that produce collagen alpha-3 (VI) chain in tumors have not been well characterized, COL6A3 gene expression and in situ hybridization data in tumors have shown that endothelial cells are the main sources. ${ }^{38}$ Compared with the expression levels in normal tissues, COL6A3 transcript or protein levels are high in multiple malignancies, such as breast cancer, ${ }^{31,33,34}$ bladder cancer, ${ }^{39,40}$ colorectal cancer, ${ }^{38,40-43}$ gastric cancer, ${ }^{44,45}$ lung cancer, ${ }^{38}$ esophageal cancer, ${ }^{38}$ pancreatic ductal adenocarcinoma, ${ }^{46,47}$ hepatocellular carcinoma, ${ }^{48,49}$ adamantinomatous craniopharyngioma, ${ }^{50}$ salivary gland carcinoma (mucoepidermoid carcinoma), ${ }^{51}$ and juvenile angiofibromas (JA). ${ }^{52}$ There are very few studies on the difference between the expression levels of the three subunits of type VI collagen in tumor tissues. In juvenile angiofibromas, although the mRNA expression levels of all three subunits of type VI collagen are high, the ratio of (alpha$1+$ alpha-2)/alpha-3 in JA is increased (93.9:1) compared with the normal control (77.5: 1) which indicates that the total degree of type VI collagen synthesis and its chain composition could be regulated in cancer progression. ${ }^{52}$ Nevertheless, COL6A3 transcript or protein levels are expressed at low levels in glioblastoma stem-like cells ${ }^{53}$ and later stage prostate cancer. ${ }^{54}$ As the stage of prostate cancer increased, COL6A3 mRNA expression decreased significantly. ${ }^{54}$ Considering the COL6A3 is mostly presented with high expression levels in the solid tumors, the issues reflected in the differences in expression levels are worth to explore.

In addition, endotrophin displays an increased level in mammary cancer cell line $\mathrm{e}^{34}$ and cancer tissues, such as colorectal cancer ${ }^{34}$ and breast cancer. ${ }^{31,33}$ Recently, scientists have discovered that endotrophin can be isolated from the plasma of breast cancer patients, and its level increased in breast cancer tissues compared with normal donor 
Table I Collagen Alpha-3 (VI) Chain and Endotrophin Exist in Different Types of Cancer

\begin{tabular}{|c|c|c|c|c|c|}
\hline Type & $\begin{array}{l}\text { Mousel } \\
\text { Human }\end{array}$ & $\begin{array}{l}\text { COL6A3 Gene/ } \\
\text { Protein }\end{array}$ & $\begin{array}{l}\text { Detection Sample } \\
\text { (Human) }\end{array}$ & Location & Ref \\
\hline Breast Cancer & Human & $\begin{array}{l}\text { Gene } \\
\text { Full length COL6A3 \& } \\
\text { C-terminal domain } \\
\text { ETP }\end{array}$ & $\begin{array}{l}\text { Cancer Tissue } \\
\text { Cancer Tissue } \\
\text { Cancer Tissue and } \\
\text { Cancer cells and Plasma }\end{array}$ & $\begin{array}{l}\text { Near the vicinity of the } \\
\text { adipocytes } \\
\text { - }\end{array}$ & $\begin{array}{l}{[37]} \\
{[36]} \\
{[31,33]}\end{array}$ \\
\hline Ovarian Cancer & Human & Gene & Cancer Cells & Epithelial cells & {$[78,80]$} \\
\hline Hepatocellular Carcinoma & Human & Gene & Cancer Tissue & - & {$[48,49]$} \\
\hline Bladder Cancer & Human & Gene & $\begin{array}{l}\text { Cancer Tissue and } \\
\text { Cancer Cells }\end{array}$ & - & {$[39,40]$} \\
\hline Glioblastoma & Human & Gene & Cancer Cells & - & {$[53]$} \\
\hline $\begin{array}{l}\text { Adamantinomatous } \\
\text { Craniopharyngioma }\end{array}$ & Human & Gene & Cancer Tissue & - & [50] \\
\hline Wilms Tumor & Human & Gene & Cancer Tissue & - & [90] \\
\hline Colon Cancer & Human & $\begin{array}{l}\text { Gene } \\
\text { Full length COL6A3 } \\
\text { ETP }\end{array}$ & $\begin{array}{l}\text { Cancer Tissue } \\
\text { Cancer Tissue } \\
\text { Cancer Tissue }\end{array}$ & $\begin{array}{l}\text { Tumor endothelium } \\
\text { - } \\
\text { - }\end{array}$ & $\begin{array}{l}{[38]} \\
{[40,62]} \\
{[31,33]}\end{array}$ \\
\hline Mouse Embryonic Fibroblasts & Mouse & Gene & Fibroblasts & - & [89] \\
\hline Esophageal Cancer & Human & Gene & Cancer Tissue & Tumor endothelium & [38] \\
\hline Gastric Cancer & Human & Gene & $\begin{array}{l}\text { Cancer Tissue/Cancer } \\
\text { Cells }\end{array}$ & - & {$[44,45]$} \\
\hline Lung Cancer & Human & Gene & Cancer Tissue & Tumor endothelium & {$[38]$} \\
\hline Pancreatic Ductal Adenocarcinoma & Human & Full length COL6A3 & Cancer Tissue & $\begin{array}{l}\text { Desmoplastic stroma around } \\
\text { the malignant ducts }\end{array}$ & {$[46,47]$} \\
\hline Tenosynovial Giant Cell Tumors & Human & Gene & Cancer Tissue & - & {$[85,87]$} \\
\hline Uterine Leiomyoma & Human & Gene & Cancer Tissue & - & {$[55]$} \\
\hline $\begin{array}{l}\text { Salivary Gland Carcinoma } \\
\text { (Mucoepidermoid Carcinoma) }\end{array}$ & Human & Gene & Cancer Tissue & - & {$[51]$} \\
\hline Prostate Cancer & Human & Gene & Cancer Tissue & - & {$[40,54]$} \\
\hline Juvenile Angiofibroma & Human & Gene & Cancer Tissue & - & {$[52]$} \\
\hline
\end{tabular}

Abbreviations: ETP, endotrophin; Ref, reference.

tissues suggests that it might be a potential biomarker in future studies. ${ }^{31}$

\section{The Role of DNA Methylation and Alternative Splicing of COL6A3 in Cancer}

A series of studies have shown that tumorigenesis and development are related to DNA methylation and its associated transcriptional aberration. ${ }^{55}$ Recent studies have demonstrated that methylation of the collagen-associated gene COL6A3 is involved in tumor development in uterine leiomyomas. Compared with myometrium, COL6A3 is less methylated and transcriptionally upregulated in uterine leiomyoma. The aberrant DNA methylation of the promoter of COL6A3 might affect the abnormal response of estrogen by affecting the expression of COL6A3 protein and promote the production of uterine leiomyoma. ${ }^{55}$ In addition, methyl-sensitive cut counting analysis (MSCC) data has shown 1.61 fold decreases in COL6A3 gene $\mathrm{CpG}$ methylation sites in glioblastoma multiforme (GBM) which suggests the potential clinical application of this epigenetic biomarker of COL6A3 in GBM. ${ }^{56}$ Together, these findings indicate that aberrant DNA methylation of COL6A3 may get involve into the tumor progression by affecting COL6A3 expression and may also have diagnosis and prognosis promises in cancer.

Alternative splicing is a biological process in which pre-mRNAs are spliced in different ways, and the resulting molecules play a critical role in protein diversity and complexity. ${ }^{57,58}$ Alternatively spliced transcripts are associated with the progression of multiple cancers. ${ }^{59}$ The repeating vWF-A domains N2-N10 at the N-terminus of 
the alpha-3 (VI) chain, are each encoded by a separate exon (exon 3 - exon 11). The three vWF-A domains of N7, N9, and N10 in these exons can be alternately spliced in human to produce multiple alpha-3 (VI) chains variants, resulting in the lack of one to three vWF-A domains in the final alpha-3 (VI) chain. ${ }^{3,9,60}$ Later study also identified the less abundant alternative transcript variants that lack a large part of the N3 and the entire N5 vWF-A domains in human cells. ${ }^{61}$ (Figure 1) Recently, studies found multiple differential splice variants of COL6A3 in different type of cancers. ${ }^{40,62}$ The tumor-specific alternative splicing of the exons 3 and exon 4 of COL6A3 in colon cancer, $^{62}$ as well as the exon 6 of COL6A 3 in colon, bladder and prostate cancers were identified by using the whole-genome exon array. ${ }^{40}$ (Figure 1) Moreover, The inclusion of exons 3, 4 and 6 of COL6A3 were mainly identified in pancreatic ductal adenocarcinoma (PDA) and the PDA cell lines, but less identified or absent from the PDA surrounding tissue and the PDA premalignant lesions. Notably the Exon 6 of COL6A3 was not only identified in PDA compared with the surrounding adjacent tissues, but also identified in all type of the PDA cell lines. In addition, the collagen alpha-3 (VI) chain was produced at high levels by cancer-associated fibroblasts and tumor cells in an in vivo xenograft model using the H766T PDA cell line. Also the COL6A3 protein deposited in connective tissue, fibroblasts and a population of transforming ductal cells in pancreatic intraepithelial neoplasias (PanINs, defined as a preinvasive state of PDA) from the LSL-KRAS $^{\mathrm{G} 12 \mathrm{D}}$;PDX-1-Cre mice (a mouse model which could develop PanINs progressed eventually to the invasive pancreatic cancers). These evidences mentioned above indicate that the malignant progression of PDA may be related to the dynamic process of COL6A3 alternative splicing. ${ }^{46}$ Further, one study also investigated the alternative splicing patterns of genes related to energy metabolism from the Cancer Genome Atlas (TCGA) RNA-Seq datasets in colorectal cancer (CRC). COL6A3 displayed with differentially expressed alternative transcripts even though the overall expression of COL6A3 gene was not significantly altered in $\mathrm{CRC}$, and the alternative transcript NM_057167 of COL6A3 (Transcript variant 5 that lacks an alternate exon 3) was strongly upregulated in colorectal, breast, lung, prostate, and kidney tumors. ${ }^{43}$ Although there is currently no specific mechanism by which COL6A3 alternative splicing affects tumor progression, the researches of COL6A3 mRNA and protein isoforms could contribute to the assessment of tumor carcinogenesis and tumor biomarker potential. Together, these evidences strongly suggest that it is important to investigate COL6A3 alternative splicing factors and their mechanism to find specific alternative splicing inhibitors for targeted cancer therapy.

\section{The Relationship Between the Collagen Alpha-3 (VI) Chain/ Endotrophin and Adipose Tissue in Cancer}

Adipocytes embed into the extracellular matrix and are considered to be endocrine cells, thus carrying the ability to secrete multiple signaling components such as chemokines, adipokines, and ECM constituents under the stimulation of hormones and nutritional cues. Adipocytederived factors such as TNF- $\alpha$, leptin, monocyte chemotactic protein-1 (MCP-1) and ECM components play an important role in tumor progression. ${ }^{63}$ Specifically, collagen VI is a highly enriched extracellular matrix component of adipose tissue. Lack of collagen VI can cause swelling of adipocyte, as well as the loose and disorder of tissue structure. ${ }^{64}$

Currently most of the researches on the biological mechanism of collagen alpha-3 (VI) chain and endotrophin in cancer have focused on breast cancer. One of the main reasons is that adipocytes are the main component of breast tumor stroma, ${ }^{78}$ which contribute to the malignant progression of breast cancer. ${ }^{34}$ Previously, scientists only found that the level of the carboxy-terminal domains of the collagen alpha-3 (VI) chain displayed significant high in murine and human breast cancer lesions compared to the rest part of the collagen alpha-3 (VI) chain. ${ }^{33}$ This carboxy-terminal domains had the signal transduction ability and promote breast tumor cell proliferation. ${ }^{33}$ However, at the time the mechanism of how this carboxy-terminal domain fragment contributed to breast cancer progression was poorly understood. In time, it was discovered that the carboxy-terminal domains' cancer-promoting effect of collagen alpha-3 (VI) chain driven by adipose tissue is exerted by the $\mathrm{C} 5$ domain cleavage fragment, also known as endotrophin. In an obesity-related environment, overexpression of endotrophin in the MMTV-PyMT (mouse mammary tumor virus/polyoma virus middle $\mathrm{T}$ oncogene) breast cancer animal model can augment tumor growth and metastasis. $^{34}$

Specifically, in the metabolically unhealthy adipose tissue associated microenvironment endotrophin can 
trigger fibrosis and inflammation in adipose tissue and ultimately lead to increased insulin resistance. Blocking endotrophin with neutralizing antibodies can improve adverse metabolic reactions and effectively reverse metabolic dysfunction induced during the HFD (high fat diet) exposure. ${ }^{35}$ Further, knockdown of COL6A3 in adipocytes leads to the development of inflammatory resistance (A state of reduced sensitivity to inflammation) via suppression of monocyte chemoattractant protein (MCP1) induction, resulting in increased adipocyte function and insulin sensitivity. ${ }^{65}$ These studies demonstrate the importance of COL6A3 and endotrophin function into the inflammation promoting process in adipose tissue.

In respect of the regulatory mechanism of endotrophin in breast cancer, endotrophin augments breast cancer inflammation and angiogenesis through recruitment of macrophages and endothelial cells. The malignant progression of breast cancer is also processed through TGF- $\beta$-dependent EMT (epithelial-mesenchymal transition) and fibrosis from endotrophin signaling transduction. ${ }^{34}$ (Figure 3) These results were proved both in vivo PyMT (A mouse model that features fast development of late-stage carcinoma and pulmonary metastasis) and PyMT/ETP (PyMT mouse model treated with endotrophin), and vitro cell lines. In the tumor microenvironment, the breast tumor tissue of the PyMT/ETP mouse reveals an enhancement of inflammatory cytokine levels, such as IL6 and TNF- $\alpha$. Compared with the control PyMT mouse model, the functional blood vessel area in the PyMT/ETP breast tumor tissues increased 3-fold with a reduction in hypoxia, and angiogenesis markers such as CD31, VEGFR2, and HIF1 $\alpha$ were increased. These effects of endotrophin as the chemokine can be reduced after treatment with endotrophin antibody. ${ }^{34}$

In spite of the regulatory mechanism, the signal transduction receptors of endotrophin is still largely unknown. Study implicates that tumor endothelial marker 8 (TEM8, an integrin-like protein localized on the surface of tumor endothelial cells and shows high levels on tumor blood vessels ${ }^{66}$ ) is a receptor for endotrophin on tumor endothelial cells because TEM8 can bind to the $\mathrm{C} 5$ domain of collagen alpha-3 (VI) chain. ${ }^{38}$ The COL6A3 and TEM8 transcripts can be co-localized in the endothelium of colon cancer, lung cancer, and esophageal cancer, and the coordinated expression of these two proteins is almost undetectable in normal tissues corresponding to tumors ${ }^{38}$ which indicate that the binding of TEM8 and endotrophin contributes to the regulation of tumor angiogenesis. Additionally, collagen VI can activate the downstream
Akt/ $\beta$-catenin signaling pathway and stabilize cyclin D1 by binding the $\mathrm{NG} 2$ /chondroitin sulfate proteoglycan signaling receptor expressed on the surface of mammary ductal epithelial cells, thereby promoting the malignant progression of breast cancer cells. ${ }^{33}$ It is still unknown whether the binding of NG2 to the collagen VI is through the interactions with endotrophin.

In summary, the role of endotrophin driven by adipose tissue in tumors is currently the clearest direction for COL6A3 in the field of tumor research while the other research directions are rarely reported in the published literatures. However, because endotrophin is a soluble cleavage fragment of collagen a3 (VI) chain, which can be secreted by a variety of tissue cell types, not just adipocytes, the mechanism of endotrophin in other types of cancer is also worth exploring.

\section{The Function of the Collagen Alpha-3 (VI) Chain/Endotrophin in Cancer}

\section{Tumor Proliferation}

In vitro, silencing COL6A3 induced a decline in cell proliferation in bladder cancer cell lines, ${ }^{39}$ colorectal cancer cell lines ${ }^{67}$ and gastric cancer cell lines. ${ }^{68}$ In an in vivo experiment, the overexpression of endotrophin in the MCF-7 breast cancer cell line manifested a significantly faster rate of tumor growth than that in control cells in the nude mouse model. ${ }^{31}$ In the PyMT mouse model, endotrophin can also augment primary tumor growth. ${ }^{34}$ Furthermore, endotrophin-neutralizing antibodies suppressed tumor growth in a nude mouse model based on MCF-7 cells, MDA-MB-231 cells, and SKOV3 cells carrying human cancer mutations. ${ }^{31}$ As sulindac is a promising non-steroidal anti-inflammatory drug for colorectal cancer. It is worth noting that in a study of sulindac-treated ApcMin/1 mice (a genetic model of human familial adenomatous polyposis), although the intestinal adenoma lesions of ApcMin/1 mice were reduced by more than $80 \%$ after treatment, the genetic microarray analyses of adenoma-derived dysplastic epithelial cells revealed surprising upregulation of type I collagen, type $\mathrm{V}$ collagen and certain subunits of type VI collagen including COL6A3. The relationship between the increase in type I collagen, type V collagen and type VI collagen subunits and the decrease in tumor burden was unclear and may involve an oxidative metabolite of sulindac-sulindac sulfone. The result indicates that tumor cells may directly 
remodel their ECM microenvironment to increase their survival in the presence of non-steroidal antiinflammatory drug. ${ }^{69}$ The regulations seen in different experiments could be a result of the complexity of the ECM microenvironment and suggests that more detailed investigations should be performed to determine the detailed mechanism by which the collagen alpha-3 (VI) chain impacts tumor proliferation.

\section{Tumor Metastasis and Invasion}

In vitro, endotrophin acted on breast cancer cell lines (MCF-7, ZR-75-1, MDA-MB-453, and MDA-MB-231) to enhance the overall migration behavior. In addition, endotrophin stimulated tube formation and contributed to the invasion ability of human umbilical vein endothelial cells (HUVECs, a lab model system for the study of the endothelial cells) in the tube formation assay (An in vitro assay used to model the recombination stage of angiogenesis, measuring the ability of endothelial cells to form capillary-like structure (also called tube). ${ }^{31}$ Additionally, COL6A3 knockout by using CRISPR/Cas9 induced a decline in cell metastasis and invasion ability in the colorectal cancer cell line SW480. ${ }^{67}$ Silencing COL6A3 by using shRNA also inhibited the cell metastasis and invasion ability in gastric cancer cell lines BGC-823 and SGC-7901. ${ }^{68}$ In vivo, endotrophin synergizes with the canonical TGF- $\beta$ pathway to promote PyMT/ETP mouse lung metastasis. ${ }^{34}$

\section{Tumor Apoptosis}

The collagen alpha-3 (VI) chain and endotrophin may get involved in tumor pro-apoptotic and tumor anti-apoptotic mechanisms. Knockout of the COL6A3 in the colorectal cancer cell line SW480 by using the CRISPR/Cas9 system led to cell cycle arrest in S phase, and the knockout effect mostly induced early apoptosis rather than late apoptosis. ${ }^{67}$ It is still unknown why knockout of the COL6A3 in SW480 affect mostly the early apoptosis. Additionally, silencing the COL6A3 gene in a gastric cancer cell line stimulates cell apoptosis through the PI3K/Akt pathway. ${ }^{68}$ While other studies have demonstrated that high levels of endotrophin can induce JNK-dependent hepatocyte apoptosis in injured hepatocytes. ${ }^{49}$ However, elevated local endotrophin levels conveyed higher antiapoptotic indices in normal mammary epithelial cells. ${ }^{34}$

In summary, endotrophin can not only promote tumor proliferation, migration and invasion in cancer progression, but may also be functioned as pro-apoptotic and anti- apoptotic factors to regulate cell apoptosis through complex mechanisms in different cancer pathological stages. Further studies need to be performed to discover the exact apoptosis mechanism that endotrophin could function into. Besides that, the collagen alpha-3 (VI) chain has the ability to promote tumor proliferation, metastasis and invasion, and can also induce anti-apoptosis processes of tumor cells. However, the functional studies of COL6A3 are mainly carried out by knocking down or knocking out the COL6A3 gene. Although collagen alpha-3 (VI) chain plays an important role in the stable assembly of collagen VI, it is not clear whether the effect of collagen alpha-3 (VI) chain on tumor behavior is by affecting the collagen VI structure stability, or either by affecting the signal transduction ability of collagen VI molecules, or both.

\section{Collagen Alpha-3 (VI) Chain and Drug Resistance}

Cisplatin is a chemotherapy drug that functions in antitumor treatment in multiple malignancies, such as lung, ovarian, bladder, and testicular cancers. ${ }^{70}$ It is the most efficacious agent against ovarian cancer, with a $40 \%-80 \%$ initial response rate. $^{71}$ Antitumor drug resistance is a common appearance in tumor malignant progression and a major cause of cancer death. This problem is extremely serious in cisplatin-resistant ovarian cancer patients, of whom a large proportion of women with cancer that initially respond to cisplatin will eventually relapse with drug-resistant disease, with death as a frequent outcome of this drug resistance. ${ }^{72}$ The underlying molecular mechanism might be due to the intrastrand and interstrand crosslinks cisplatin forms in DNA, which trigger cell cycle arrest and apoptosis in cancer cells. ${ }^{73,74}$ However, data suggests that cisplatin resistance is regulated by a variety of factors, ${ }^{73}$ including inactivation of molecular interactions ${ }^{75}$ and decreased intracellular levels of cisplatin. ${ }^{76}$ In the tumor microenvironment, ECM components might function in chemotherapy resistance due to cancer cell and stromal cell interactions. ${ }^{77}$ In recent years, after large-scale gene expression analyses of tumor cells by using cDNA arrays and gene expression sequence analysis (SAGE) technology, scientists have obtained much information about cisplatin-induced gene expression changes, and a study has found that many ECM genes are altered in cisplatin-resistant A2780 ovarian cancer cell line. COL6A3 is one of major upregulated genes and a role for collagen VI in cisplatin resistance is supported by the finding that cisplatin sensitivity is reduced in the presence of collagen VI protein in vitro. ${ }^{78}$ As a fragment secreted in the 
ECM, endotrophin affects cisplatin drug resistance in tumors. One study found that the human breast cancer cell line MCF-7, which expressed endotrophin at a low level, was susceptible to cisplatin. However, MCF-7 cells showed cisplatin resistance after treatment with recombinant endotrophin. Such resistance can also be reversed by treatment with the antibody ETPmAb4 (a rabbit monoclonal antibody designed specifically against human endotrophin), resulting in increased cisplatin sensitivity in a dose-dependent manner. ${ }^{31}$ Another example is that in a mammary tumor model, endotrophin can induce cisplatin resistance by enhancing epithelial-mesenchymal transition; in turn, cisplatin exposure accelerates the upregulation of COL6A3 expression. However, such drug resistance can be reversed by thiazolidinediones (TZDs) treatment or antiendotrophin treatment. (Figure 3) TZDs is a peroxisome proliferator-activated receptor gamma (PPARg) agonists used in the combination therapies with the chemotherapy drugs in cancer treatment. Studies showed that the combination therapies with TZDs can reduce the overall systemic toxicity to the chemotherapy regimens and promote cancer cell death. These results suggests that the TZDs combination therapy can benefit the platinum-based chemotherapy in breast cancer through the anti-endotrophin effect of TZDs. ${ }^{79}$

Apart from cisplatin resistance, gene expression analysis of samples with platinum drug resistance using the clonal subline A2780/C10B isolated from the oxaliplatinresistant human ovarian carcinoma cell line A2780/C10 (18-fold resistance to oxaliplatin and 3-fold crossresistance to cisplatin) showed that COL6A3 was the most highly expressed gene, with a 62-fold change. Hence, there is a possibility that COL6A3 can function in other platinum drug resistance processes. ${ }^{80}$

A previous study also found that the naturally occurring somatic mutation Y537S in the estrogen receptor gene (ESR1) was specifically associated with acquired resistance to hormonal therapies, such as tamoxifen, a hormone therapy drug used to treat breast cancers. Moreover, in breast cancer cells with the MCF-7/Y537S mutation, proteomics analysis revealed that tamoxifen drug resistance was correlated with the overexpression of several poor clinical outcome-associated protein markers. COL6A3 was one of them, which indicates that COL6A3 could play an important role in the tamoxifen resistance process in cancer. ${ }^{81}$

In short, endotrophin can not only reduce the drug sensitivity of cisplatin during cancer treatment but also has the potential to affect the sensitivity of other platinum drugs and hormone therapies.

\section{Potential Diagnostic and Prognostic Role of COL6A3 and Endotrophin in Cancer Detection}

Since COL6A3 has been found to be highly expressed in various tumor types, endotrophin can be isolated from the plasma of cancer patient, and the COL6A3 gene has been discovered to have differential expression before and after radiotherapy in $\mathrm{CRC},{ }^{82} \mathrm{COL} 6 \mathrm{~A} 3$ and endotrophin represent potential markers that can be assessed noninvasively for cancer detection. For example, receiver operating characteristic (ROC) curve analyses for the diagnostic evaluation of COL6A3 in CRC patients revealed an area under the curve of 0.885 and a sensitivity and specificity of $92.9 \%$ and $81.3 \%$, respectively, which indicates that COL6A3 could be used as a useful diagnostic indicator. ${ }^{41}$ In addition, as the tumorspecific alternative splicing of exon 6 in colon, bladder and prostate cancers almost exclusively expressed in cancer samples, it is possible that this COL6A3 mRNA and protein isoform could be used as a potential diagnostic biomarker. ${ }^{45}$

In terms of applications in tumor prognostic detection, studies have found that upregulated mRNA and protein expression of COL6A3 in CRC indicates a poor prognosis. What's more, high expression of COL6A3 in CRC is significantly associated with clinical factors such as Dukes stage, T stage, and recurrence. ${ }^{41}$ In addition, $C O L 6 A 3$ was featured in a novel 5-gene (SMAD4, MUC16, COL6A3, FLG, and LRP1B) prognostic panel constructed through sequencing and data training of 338 cases of colorectal cancer. The prognostic panel was further verified in the dataset from patients with stage III colon cancer and proved it prognostic value. ${ }^{83}$ Another study also included COL6A3 in a 5-gene signature (SMAD4, TMEM132D, VCAN, CDH10, and COL6A3) in which mutations in one or more of the genes were significantly associated with better overall survival independent of tumor-nodemetastasis (TNM) staging, which suggests its potential role in CRC prognosis. ${ }^{84}$ Because of the anti-ETP effect of TZDs, endotrophin levels also serve as a strong prognostic marker for the effectiveness of the combination therapy of TZDs and cisplatin. ${ }^{79}$ Together, these findings strongly support the idea that COL6A3 or endotrophin expression can be used as a useful prognostic and drug sensitivity indicator.

\section{COL6A3 and CSFI in Tenosynovial Giant Cell Tumors}

Tenosynovial giant cell tumors (TGCTs) are a type of benign lesion of the tendon sheaths primarily affecting the fingers, ankles, and feet. TGCTs are derived from the overexpression 
of rearranged macrophage colony-stimulating factor (CSF1), which causes tumor growth and recruitment of nonneoplastic mononuclear and multinucleated inflammatory cells. ${ }^{85-87}$ Previous studies have confirmed the existence of the fusion gene CSF1-COL6A3 in TGCTs by RT-PCR. Due to a strong COL6A3 promoter, a fusion of the CSF1-COL6A3 genes through the translocation would result in overexpression of CSF1. ${ }^{85,86}$ However, recently, in a large cohort study, TGCTs were reported to feature truncation of the $3^{\prime}$ end of CSF1 and were characterized by variable alterations, not the previously identified COL6A3-CSF1 fusion genes found in some TGCTs. $^{87}$

\section{Conclusion and Future Perspective}

In this review, we summarize the expression and function of the collagen alpha-3 (VI) chain and the polypeptide fragment endotrophin, which are both highly expressed in a variety of cancers. Endotrophin plays a crucial role in in adipocyte-driven cancer progression. The endotrophin signaling directly affects cancer cell malignancy through the TGF- $\beta$-dependent pathway, inducing epithelial-mesenchymal transition and fibrosis. Moreover, endotrophin regulates the cancer microenvironment by enhancing the chemoattractant effect on the macrophages and endothelial cells, eventually promoting cancer inflammation and angiogenesis. Nevertheless, it is not clear whether the regulation of tumor progression through silencing COL6A3 is achieved by affecting the collagen VI molecular structure or the signal transduction function. In addition, we also summarize the current knowledge on cancer chemotherapy drug resistance and the alternative splicing of COL6A3 in cancer. Endotrophin can induce cisplatin resistance in cancer by enhancing epithelial-mesenchymal transition. Also, the tumor-specific alternative splicing of COL6A3 may have a certain effect on the malignant progression in cancer.

In spite of an increasing number of studies have revealed the importance of collagen alpha-3 (VI) chain and endotrophin in tumorigenesis, many questions remain in this field (question box). For example, it is still unclear how collagen alpha-3 (VI) chain/endotrophin function in other collagen VI and endotrophin enriched tumor tissue. Due to the assembly characteristics of collagen VI subunits, the previous research field only focused on the role of COL6A3 itself in tumors. Obviously, more attentions need to be paid on the dynamic changes of collagen VI subunits in tumors in the future. Besides, limited insights have been put into the proteolytic process of the C-terminal domains of collagen alpha-3 (VI) chain that cleavage into multiple endotrophin-containing fragments. Recently, scientists only have found that the bone morphogenetic protein 1 (BMP-1) is involved in the endotrophin release process via the cleavage site between the $\mathrm{C} 4$ and C5 domains. Moreover, a large C2-C5 fragment that contains endotrophin is cleaved between the $\mathrm{C} 1$ and $\mathrm{C} 2$ domains by furin-like proprotein convertase. ${ }^{20}$ (Figure 2) The existence of these endotrophin-containing fragments in tissue and cell cultures ${ }^{20}$ raises the question of whether these endotrophincontaining fragments function the same way as endotrophin does in tumor progression or whether it might work differently. Another concern is whether the C2-C5 fragment will affect laboratory tests specific for endotrophin. In addition, one matrix metalloproteinase (MMPs) cleavage site on collagen alpha-3 (VI) chain has also been described recently, but with less experimental evidence. ${ }^{88}$ The cleavage fragment produced by MMPs is C6Ma3, a new epitope on the alpha-3 (VI) chain which needs further study to confirm the exact cleavage site. Furthermore, as we mention in the review, COL6A3 is aberrantly methylated and alternative spliced in cancer. This raises the question of how these aberrantly methylated and alternatively spliced forms affect the malignant progression of cancers. Finally, the question that whether endotrophin gets involved in drug resistance other than cisplatin in cancer, for example, the hormonal therapy drugs.

There are also some other studies worth noticing, COL6A3 is highly expressed in densely growing mouse embryonic fibroblasts (MEFs) and promotes the 3D growth of MEFs by suppressing the Hippo signaling pathway and promoting the Wnt signaling pathway. (Figure 3) Additionally, the high expression of COL6A3 in Taf4 ${ }^{-/}$ MEFs promotes the loss of contact inhibition. As the Hippo signaling pathway is considered to be an essential part of cancer cell contact inhibition, ${ }^{89}$ in this regard, COL6A3 participates in the hallmark of evading growth suppressors in MEFs, which suggests that it might function the same way in cancer. Besides, downregulated COL6A3 in glioblastoma stem-like cells also suggests that COL6A3 can participate in replicative immorality in cancer stem cells. ${ }^{53}$ Moreover, genome-wide sequencing has identified gene mutations in COL6A3 in Wilms tumors, ${ }^{90}$ and this evidence reminds us that genome mutations in COL6A3 may appear in other types of tumors. Whether the mutations of COL6A3 gene in tumor will affect the molecular structure and assembly of collagen VI, thus affect the downstream signaling pathway needs further research.

Finally, clinical applications of endotrophin are expected. Multiple studies have proven its prognostic value by using a commercially available ELISA for 


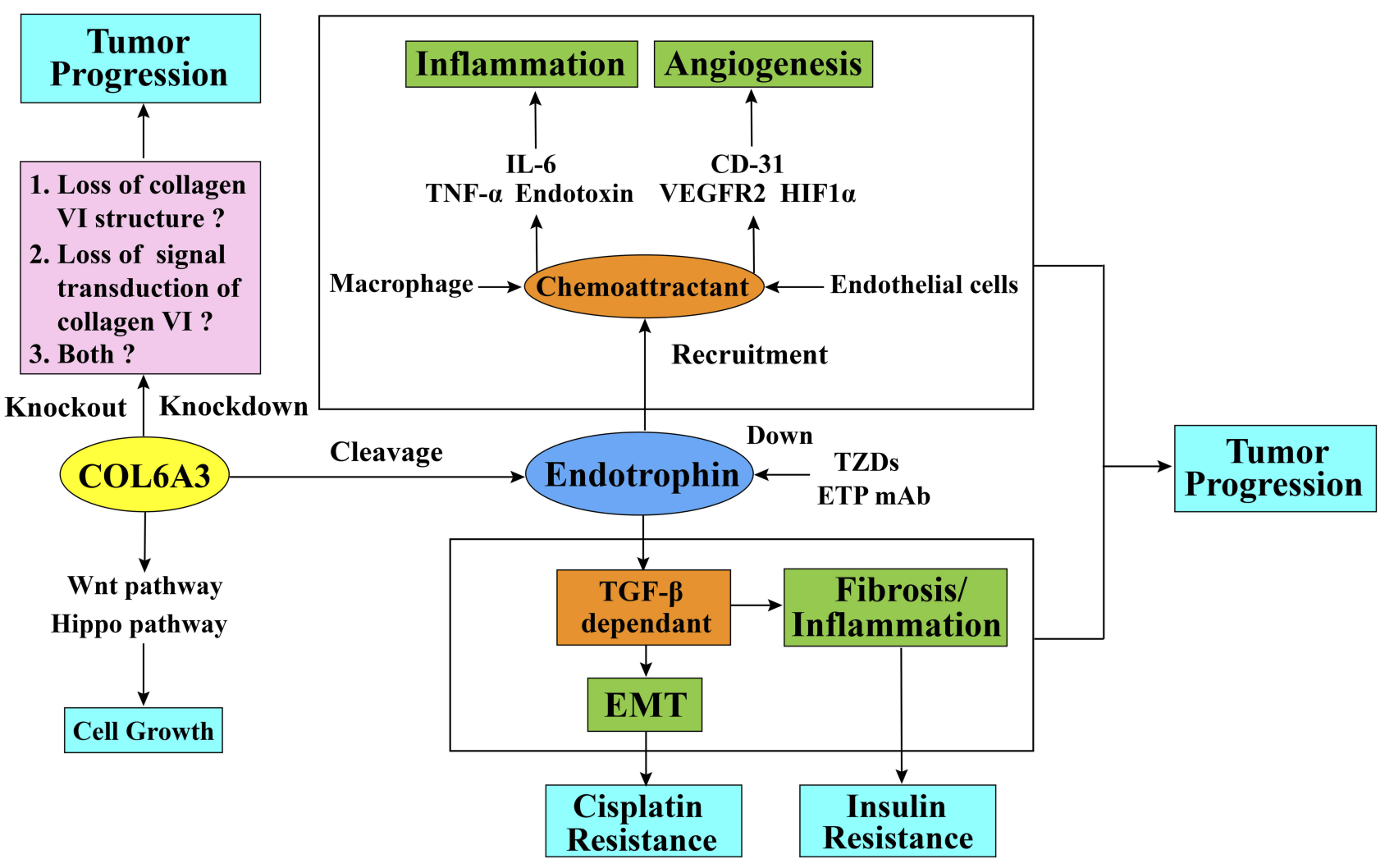

Figure 3 Schematic diagram of collagen alpha-3 (VI) chains and endotrophin function in tumor progression and cisplatin resistance. The collagen alpha-3 (VI) chain C5 domain fragment endotrophin regulates tumor EMT and fibrosis through a TGF- $\beta$-dependent pathway. Endotrophin can also promote tumor inflammation through the recruitment of macrophages and enhances the expression level of inflammatory cytokines, such as IL6 and TNF- $\alpha$, or through the recruitment of endothelial cells into the tumor microenvironment to promote tumor angiogenesis and increase the expression level of angiogenesis markers, such as CD3I, VEGFR2, and HIFI $\alpha$. It is not clear whether the effect of collagen alpha-3 (VI) chain on tumor behavior is by affecting the collagen $\mathrm{VI}$ structure stability, either by affecting the signal transduction ability of collagen $\mathrm{VI}$ molecules, or both. In terms of drug resistance, endotrophin can induce tumor cells to resist cisplatin through the TGF- $\beta$-EMT pathway, and treatment with endotrophin mAb or TZDs can block this process by downregulating endotrophin levels and eventually give rise to increased cisplatin sensitivity. Additionally, COL6A3 is highly expressed in densely growing mouse embryonic fibroblasts (MEFs) and promotes the 3D growth of MEFs by suppressing the Hippo signaling pathway and promoting the Wnt signaling pathway.

Abbreviations: TGF- $\beta$, transforming growth factor beta; EMT, epithelial-mesenchymal transition; IL-6, interleukin 6; TNF- $\alpha$, tumor necrosis factor alpha; CD-3I, cluster of differentiation 3I; VEGFR2, vascular endothelial growth factor receptor 2; HIFI $\alpha$, hypoxia-inducible factor I $\alpha$; ETP, endotrophin; mAb, monoclonal antibodies; TZDs, thiazolidinediones.

endotrophin (also named PRO-C6) in other diseases. ${ }^{91}$ The PRO-C6 test is being used for human serum samples to evaluate the progression of multiple diseases, such as systemic sclerosis, ${ }^{92}$ diabetes $^{93,94}$ and chronic obstructive pulmonary disease (COPD). ${ }^{95-98}$ In tumor, the PRO-C6 can be used for prognostic monitoring. The high level of PRO-C6 in pre-treatment can predict the prognosis of chemotherapy in patients with metastatic colorectal cancer. ${ }^{99}$ Although several studies have proved the prognostic abilities of endotrophin, there is still a long way to go before clinical use. Most importantly, regarding therapeutic applications, we know that endotrophin antibodies can inhibit tumor growth in animal models, but it remains unclear whether endotrophin antibodies have the same antitumor effects in humans. Additionally, as endotrophin is a ligand for TEM $8,{ }^{38}$ and the interaction between these two molecules raises an interesting question: If endotrophin can be used as a novel therapeutic target to modulate TEM8-targeted tumor vasculature. There has been antitumor efficacy from TEM8-targeted therapy using the TEM8 ligand fused to anthrax toxin. ${ }^{38}$ More in-depth mechanistic research and drug experiments are needed in this field.

To conclude, this review highlights the biological function of the collagen alpha-3 (VI) chain and endotrophin in cancer, the problems within this field, and future clinical applications.

Question Box:

1. How collagen alpha-3 (VI) chain/endotrophin function in tumor tissues that are rich in collagen type VI other than breast cancer?

2. What are the differences in the expression levels of collagen VI subunits in tumors? 
3. Does silencing COL6A3 affect collagen VI structure or signal transduction?

4. In addition to TEM8, are there any other signaling molecule receptors for endotrophin?

5. Does the N-terminal global-like domains of collagen alpha-3 (VI) chain have the signal transduction function in tumors?

6. Whether the alpha-5 (VI) and alpha-6 (VI) chains can replace alpha-3 (VI) chain in cancer.

7. Can endotrophin-containing fragments function the same way as endotrophin in tumor progression, or does it work differently? What is the potential mechanism? Will these endotrophin-containing fragments affect laboratory tests for endotrophin if it is also recognized by endotrophin antibodies?

8. Is endotrophin involved in resistance to drugs other than cisplatin, for example, resistance to hormonal therapies in cancer?

9. How do aberrant DNA methylation and alternative splicing of COL6A3 affect tumor progression?

10. Can endotrophin antibodies function as potent antitumor drugs and have the same effects in clinical drug experiments as they do in in vitro experiments?

\section{Acknowledgment}

This study was funded by the Zhejiang Provincial Medicine and Health Major Plan of Science and Technology (grant number: 2018258924), as well as Major Science and Technology Project of Zhejiang Provincial Department of Science and Technology (grant number: 2020C03030). Figure 1 was adapted with permission from the Journal of Cell Science. ${ }^{100}$ Figure 2 was adapted with permission from The Biochemical journal. ${ }^{101}$

\section{Disclosure}

The authors report no conflicts of interest in this work.

\section{References}

1. Lu P, Weaver VM, Werb Z. The extracellular matrix: a dynamic niche in cancer progression. J Cell Biol. 2012;196(4):395-406. doi:10.1083/ jcb.201102147

2. Chen P, Cescon M, Bonaldo P. Collagen VI in cancer and its biological mechanisms. Trends Mol Med. 2013;19(7):410-417. doi:10.1016/j. molmed.2013.04.001

3. Zanussi S, Doliana R, Segat D, Bonaldo P, Colombatti A. The human type VI collagen gene. mRNA and protein variants of the alpha 3 chain generated by alternative splicing of an additional 5-end exon. J Biol Chem. 1992;267(33):24082-24089.
4. Demir E, Sabatelli P, Allamand V, et al. Mutations in COL6A3 cause severe and mild phenotypes of Ullrich congenital muscular dystrophy. Am J Hum Genet. 2002;70(6):1446-1458. doi:10.10 86/340608

5. Lamandé SR, Mörgelin M, Adams NE, Selan C, Allen JM. The C5 domain of the collagen VI alpha3(VI) chain is critical for extracellular microfibril formation and is present in the extracellular matrix of cultured cells. J Biol Chem. 2006;281(24):16 607-16614. doi:10.1074/jbc.M510192200

6. Bonaldo P, Russo V, Bucciotti F, Bressan GM, Colombatti A. Alpha 1 chain of chick type VI collagen. The complete cDNA sequence reveals a hybrid molecule made of one short collagen and three von Willebrand factor type A-like domains. $J$ Biol Chem. 1989;264(10):5575-5580.

7. Bonaldo P, Russo V, Bucciotti F, Doliana R, Colombatti A. Structural and functional features of the alpha 3 chain indicate a bridging role for chicken collagen VI in connective tissues. Biochemistry. 1990;29(5):1245-1254. doi:10.1021/bi00457a021

8. Chu ML, Zhang RZ, Pan TC, et al. Mosaic structure of globular domains in the human type VI collagen alpha 3 chain: similarity to von Willebrand factor, fibronectin, actin, salivary proteins and aprotinin type protease inhibitors. EMBO J. 1990;9(2):385-393. doi:10.1002/j.1460-2075.1990.tb08122.x

9. Doliana R, Bonaldo P, Colombatti A. Multiple forms of chicken alpha 3(VI) collagen chain generated by alternative splicing in type A repeated domains. $J$ Cell Biol. 1990;111(5 Pt 1):2197-2205. doi:10.1083/jcb.111.5.2197

10. Bernardi P, Bonaldo P. Dysfunction of mitochondria and sarcoplasmic reticulum in the pathogenesis of collagen VI muscular dystrophies. Ann N Y Acad Sci. 2008;1147(1):303-311. doi:10.11 96/annals.1427.009

11. Sabatelli P, Gara SK, Grumati P, et al. Expression of the collagen VI alpha5 and alpha6 chains in normal human skin and in skin of patients with collagen VI-related myopathies. J Invest Dermatol. 2011;131(1):99-107.

12. Aigner $\mathrm{T}$, Hambach $\mathrm{L}$, Söder $\mathrm{S}$, Schlötzer-Schrehardt $\mathrm{U}$, Pöschl E. The C5 domain of Col6A3 is cleaved off from the Col6 fibrils immediately after secretion. Biochem Biophys Res Commun. 2002;290(2):743-748. doi:10.1006/bbrc.2001.6227

13. Fitzgerald J, Rich C, Zhou FH, Hansen U. Three novel collagen VI chains, alpha4(VI), alpha5(VI), and alpha6(VI). J Biol Chem. 2008;283(29):20170-20180. doi:10.1074/jbc.M710139200

14. Gara SK, Grumati P, Urciuolo A, et al. Three novel collagen VI chains with high homology to the alpha3 chain. $J$ Biol Chem. 2008;283(16):10658-10670. doi:10.1074/jbc.M709540200

15. Engel J, Furthmayr H, Odermatt E, et al. Structure and macromolecular organization of type VI collagen. Ann N Y Acad Sci. 1985;460:25-37. doi:10.1111/j.1749-6632.1985.tb51154.x

16. Colombatti A, Bonaldo P, Ainger K, Bressan GM, Volpin D. Biosynthesis of chick type VI collagen. I. Intracellular assembly and molecular structure. J Biol Chem. 1987;262(30):144 54-14460.

17. Colombatti A, Mucignat MT, Bonaldo P. Secretion and matrix assembly of recombinant type VI collagen. $J$ Biol Chem. 1995;270(22):13105-13111. doi:10.1074/jbc.270.22.13105

18. Colombatti A, Bonaldo P. Biosynthesis of chick type VI collagen. II. Processing and secretion in fibroblasts and smooth muscle cells. J Biol Chem. 1987;262(30):14461-14466.

19. Chu ML, Pan TC, Conway D, et al. The structure of type VI collagen. Ann N Y Acad Sci. 1990;580:55-63. doi:10.1111/j.17496632.1990.tb17917.x

20. Heumuller SE, Talantikite M, Napoli M, et al. C-terminal proteolysis of the collagen VI alpha3 chain by BMP-1 and proprotein convertase(s) releases endotrophin in fragments of different sizes. J Biol Chem. 2019;294(37):13769-13780. doi:10.1074/jbc.RA11 9.008641 
21. Fitzgerald J, Holden P, Hansen U. The expanded collagen VI family: new chains and new questions. Connect Tissue Res. 2013;54(6):345-350. doi:10.3109/03008207.2013.822865

22. Sabatelli P, Gara SK, Grumati P, et al. Expression of the collagen VI $\alpha 5$ and $\alpha 6$ chains in normal human skin and in skin of patients with collagen VI-related myopathies. J Invest Dermatol. 2011;131 (1):99-107. doi:10.1038/jid.2010.284

23. Lamandé SR, Sigalas E, Pan TC, et al. The role of the alpha3(VI) chain in collagen VI assembly. Expression of an alpha3(VI) chain lacking N-terminal modules N10-N7 restores collagen VI assembly, secretion, and matrix deposition in an alpha3(VI)-deficient cell line. J Biol Chem. 1998;273(13):7423-7430. doi:10.1074/ jbc.273.13.7423

24. Fitzgerald J, Mörgelin M, Selan C, et al. The N-terminal N5 subdomain of the alpha $3(\mathrm{VI})$ chain is important for collagen VI microfibril formation. $J$ Biol Chem. 2001;276(1):187-193. doi:10.1074/jbc.M008173200

25. Beecher N, Roseman AM, Jowitt TA, et al. Collagen VI, conformation of A-domain arrays and microfibril architecture. $J$ Biol Chem. 2011;286(46):40266-40275. doi:10.1074/jbc.M111.265 595

26. Keene DR, Engvall E, Glanville RW. Ultrastructure of type VI collagen in human skin and cartilage suggests an anchoring function for this filamentous network. J Cell Biol. 1988;107 (5):1995-2006. doi:10.1083/jcb.107.5.1995

27. Allen JM, Zamurs L, Brachvogel B, et al. Mice lacking the extracellular matrix protein WARP develop normally but have compromised peripheral nerve structure and function. $J$ Biol Chem. 2009;284(18):12020-12030. doi:10.1074/jbc.M806968 200

28. Cheng JS, Dubal DB, Kim DH, et al. Collagen VI protects neurons against Abeta toxicity. Nat Neurosci. 2009;12(2):1 19-121. doi: $10.1038 / \mathrm{nn} .2240$

29. Cheng IH, Lin YC, Hwang E, et al. Collagen VI protects against neuronal apoptosis elicited by ultraviolet irradiation via an Akt/ phosphatidylinositol 3-kinase signaling pathway. Neuroscience 2011;183:178-188. doi:10.1016/j.neuroscience.2011.03.057

30. Grumati P, Coletto L, Sabatelli P, et al. Autophagy is defective in collagen VI muscular dystrophies, and its reactivation rescues myofiber degeneration. Nat Med. 2010;16(11):1313-1320. doi:10. $1038 / \mathrm{nm} .2247$

31. Bu D, Crewe C, Kusminski CM, et al. Human endotrophin as a driver of malignant tumor growth. JCI Insight. 2019;4:5.

32. Spencer M, Yao-Borengasser A, Unal R, et al. Adipose tissue macrophages in insulin-resistant subjects are associated with collagen VI and fibrosis and demonstrate alternative activation. $\mathrm{Am}$ J Physiol Endocrinol Metab. 2010;299(6):E1016-E1027. doi:10. 1152/ajpendo.00329.2010

33. Iyengar P, Espina V, Williams TW, et al. Adipocyte-derived collagen VI affects early mammary tumor progression in vivo, demonstrating a critical interaction in the tumor/stroma microenvironment. J Clin Invest. 2005;115(5):1163-1176. doi:10. 1172/JCI23424

34. Park J, Scherer PE. Adipocyte-derived endotrophin promotes malignant tumor progression. J Clin Invest. 2012;122(11):42 43-4256. doi:10.1172/JCI63930

35. Sun K, Park J, Gupta OT, et al. Endotrophin triggers adipose tissue fibrosis and metabolic dysfunction. Nat Commun. 2014;5 (1):3485. doi: $10.1038 /$ ncomms 4485

36. Park J, Scherer PE. Endotrophin - a novel factor linking obesity with aggressive tumor growth. Oncotarget. 2012;3(12):14 87-1488. doi:10.18632/oncotarget.796

37. Mayer U, Pöschl E, Nischt R, et al. Recombinant expression and properties of the Kunitz-type protease-inhibitor module from human type VI collagen alpha 3(VI) chain. Eur J Biochem. 1994;225(2):573-580. doi:10.1111/j.1432-1033.1994.00573.x
38. Nanda A, Carson-Walter EB, Seaman S, et al. TEM8 interacts with the cleaved C5 domain of collagen alpha 3(VI). Cancer Res. 2004;64(3):817-820. doi:10.1158/0008-5472.CAN-03-2408

39. Huang Y, Li G, Wang K, et al. Collagen type VI alpha 3 chain promotes epithelial-mesenchymal transition in bladder cancer cells via transforming growth factor beta (TGF-beta)/smad pathway. Med Sci Monit. 2018;24:5346-5354. doi:10.12659/ MSM.909811

40. Thorsen K, Sorensen KD, Brems-Eskildsen AS, et al. Alternative splicing in colon, bladder, and prostate cancer identified by exon array analysis. Mol Cell Proteomics. 2008;7(7):1214-1224. doi:10.1074/mcp.M700590-MCP200

41. Qiao J, Fang CY, Chen SX, et al. Stroma derived COL6A3 is a potential prognosis marker of colorectal carcinoma revealed by quantitative proteomics. Oncotarget. 2015;6(30):29929-29946. doi:10.18632/oncotarget.4966

42. Smith MJ, Culhane AC, Donovan M, et al. Analysis of differential gene expression in colorectal cancer and stroma using fluorescence-activated cell sorting purification. $\mathrm{Br} \mathrm{J}$ Cancer. 2009;100(9):1452-1464. doi:10.1038/sj.bjc.6604931

43. Snezhkina AV, Krasnov GS, Zaretsky AR, et al. Differential expression of alternatively spliced transcripts related to energy metabolism in colorectal cancer. BMC Genomics. 2016;17(Suppl 14):1011. doi:10.1186/s12864-016-3351-5

44. Cao W, Zhou D, Tang W, An H, Zhang Y. Discovery of plasma messenger RNA as novel biomarker for gastric cancer identified through bioinformatics analysis and clinical validation. PeerJ. 2019;7:e7025. doi:10.7717/peerj.7025

45. Xie X, Liu X, Zhang Q, Yu J. Overexpression of collagen VI alpha3 in gastric cancer. Oncol Lett. 2014;7(5):1537-1543. doi:10.3892/ol.2014.1910

46. Arafat H, Lazar M, Salem K, et al. Tumor-specific expression and alternative splicing of the COL6A3 gene in pancreatic cancer. Surgery. 2011;150(2):306-315. doi:10.1016/j.surg.2011.05.011

47. Kang CY, Wang J, Axell-House D, et al. Clinical significance of serum COL6A3 in pancreatic ductal adenocarcinoma. J Gastrointest Surg. 2014;18(1):7-15. doi:10.1007/s11605-013-2326-y

48. Lai KK, Shang S, Lohia N, et al. Extracellular matrix dynamics in hepatocarcinogenesis: a comparative proteomics study of PDGFC transgenic and Pten null mouse models. PLoS Genet. 2011;7(6): e1002147. doi:10.1371/journal.pgen.1002147

49. Lee C, Kim M, Lee JH, et al. COL6A3-derived endotrophin links reciprocal interactions among hepatic cells in the pathology of chronic liver disease. J Pathol. 2019;247(1):99-109. doi:10.1002/path.5172

50. Yang J, Hou Z, Wang C, Wang H, Zhang H. Gene expression profiles reveal key genes for early diagnosis and treatment of adamantinomatous craniopharyngioma. Cancer Gene Ther. 2018;25(9-10):227-239. doi:10.1038/s41417-018-0015-4

51. Leivo I, Jee KJ, Heikinheimo K, et al. Characterization of gene expression in major types of salivary gland carcinomas with epithelial differentiation. Cancer Genet Cytogenet. 2005;156 (2):104-113. doi:10.1016/j.cancergencyto.2004.04.016

52. Gramann M, Wendler O, Haeberle L, Schick B. Prominent collagen type VI expression in juvenile angiofibromas. Histochem Cell Biol. 2009;131(1):155-164. doi:10.1007/s00418-008-0501-0

53. Fiscon G, Conte F, Paci P. SWIM tool application to expression data of glioblastoma stem-like cell lines, corresponding primary tumors and conventional glioma cell lines. BMC Bioinformatics. 2018;19(Suppl 15):436. doi:10.1186/s12859-018-2421-x

54. Schenck J, Fitzgerald JM. Analysis of COL6A3, COL6A5 and COL6A6 gene expression in breast and prostate tumors. Adv Clin Transl Res. 2018;2(2):100011.

55. Maekawa R, Sato S, Yamagata Y, et al. Genome-wide DNA methylation analysis reveals a potential mechanism for the pathogenesis and development of uterine leiomyomas. PLoS One. 2013;8(6):e66632. doi:10.1371/journal.pone.0066632 
56. Hyman G, Manglik V, Rousch JM, Verma M, Kinkebiel D, Banerjee HN. Epigenetic approaches in glioblastoma multiforme and their implication in screening and diagnosis. Methods Mol Biol. 2015;1238:511-521.

57. Black DL. Mechanisms of alternative pre-messenger RNA splicing. Annu Rev Biochem. 2003;72(1):291-336. doi:10.1146/ annurev.biochem.72.121801.161720

58. Maniatis T, Tasic B. Alternative pre-mRNA splicing and proteome expansion in metazoans. Nature. 2002;418(6894):23 6-243. doi:10.1038/418236a

59. Oltean S, Bates DO. Hallmarks of alternative splicing in cancer. Oncogene. 2014;33(46):5311-5318. doi:10.1038/onc.2013.533

60. Stokes DG, Saitta B, Timpl R, Chu ML. Human alpha 3(VI) collagen gene. Characterization of exons coding for the amino-terminal globular domain and alternative splicing in normal and tumor cells. J Biol Chem. 1991;266(13):8626-8633.

61. Dziadek M, Kazenwadel JS, Hendrey JA, Pan TC, Zhang RZ, Chu ML. Alternative splicing of transcripts for the alpha 3 chain of mouse collagen VI: identification of an abundant isoform lacking domains N7-N10 in mouse and human. Matrix Biol. 2002;21(3):227-241. doi:10.1016/S0945-053X(02)00009-4

62. Gardina PJ, Clark TA, Shimada B, et al. Alternative splicing and differential gene expression in colon cancer detected by a whole genome exon array. BMC Genomics. 2006;7(1):325. doi:10.1186/ 1471-2164-7-325

63. Henegar C, Tordjman J, Achard V, et al. Adipose tissue transcriptomic signature highlights the pathological relevance of extracellular matrix in human obesity. Genome Biol. 2008;9(1):R14. doi:10.1186/gb-2008-9-1-r14

64. Khan T, Muise ES, Iyengar P, et al. Metabolic dysregulation and adipose tissue fibrosis: role of collagen VI. Mol Cell Biol. 2009;29(6):1575-1591. doi:10.1128/MCB.01300-08

65. Gesta S, Guntur K, Majumdar ID, et al. Reduced expression of collagen VI alpha 3 (COL6A3) confers resistance to inflammation-induced MCP1 expression in adipocytes. Obesity (Silver Spring). 2016;24(8):1695-1703. doi:10.1002/oby.21565

66. Yang MY, Chaudhary A, Seaman S, et al. The cell surface structure of tumor endothelial marker 8 (TEM8) is regulated by the actin cytoskeleton. Biochim Biophys Acta. 2011;1813 (1):39-49. doi:10.1016/j.bbamcr.2010.11.013

67. Liu W, Li L, Ye H, Tao H, He H. Role of COL6A3 in colorectal cancer. Oncol Rep. 2018;39(6):2527-2536. doi:10.3892/or.2018.6331

68. Ao R, Guan L, Wang Y, Wang JN. Silencing of COL1A2, COL6A3, and THBS2 inhibits gastric cancer cell proliferation, migration, and invasion while promoting apoptosis through the PI3k-Akt signaling pathway. J Cell Biochem. 2018;119 (6):4420-4434. doi:10.1002/jcb.26524

69. Guillen-Ahlers H, Buechler SA, Suckow MA, Castellino FJ, Ploplis VA. Sulindac treatment alters collagen and matrilysin expression in adenomas of ApcMin/+ mice. Carcinogenesis. 2008;29(7):1421-1427. doi:10.1093/carcin/bgn123

70. Cohen SM, Lippard SJ. Cisplatin: from DNA damage to cancer chemotherapy. Prog Nucleic Acid Res Mol Biol. 2001;67:93-130.

71. McGuire WP, Hoskins WJ, Brady MF, et al. Cyclophosphamide and cisplatin compared with paclitaxel and cisplatin in patients with stage III and stage IV ovarian cancer. $N$ Engl $J$ Med. 1996;334(1):1-6. doi:10.1056/NEJM199601043340101

72. Ozols RF, Young RC. Chemotherapy of ovarian cancer. Semin Oncol. 1984;11(3):251-263.

73. Kartalou M, Essigmann JM. Mechanisms of resistance to cisplatin. Mutat Res. 2001;478(1-2):23-43. doi:10.1016/S00275107(01)00141-5

74. Pinto AL, Lippard SJ. Binding of the antitumor drug cis-diamminedichloroplatinum(II) (cisplatin) to DNA. Biochim Biophys Acta. 1985;780(3):167-180. doi:10.1016/0304-419x(85) 90001-0
75. Kasahara K, Fujiwara Y, Nishio K, et al. Metallothionein content correlates with the sensitivity of human small cell lung cancer cell lines to cisplatin. Cancer Res. 1991;51(12):3237-3242.

76. Gately DP, Howell SB. Cellular accumulation of the anticancer agent cisplatin: a review. Br J Cancer. 1993;67(6):1171-1176. doi:10.1038/bjc.1993.221

77. DeClerck YA. Interactions between tumour cells and stromal cells and proteolytic modification of the extracellular matrix by metalloproteinases in cancer. Eur $J$ Cancer. 2000;36(10):1258-1268. doi:10.1016/S0959-8049(00)00094-0

78. Sherman-Baust CA, Weeraratna AT, Rangel LB, et al. Remodeling of the extracellular matrix through overexpression of collagen VI contributes to cisplatin resistance in ovarian cancer cells. Cancer Cell. 2003;3(4):377-386. doi:10.1016/S15356108(03)00058-8

79. Park J, Morley TS, Scherer PE. Inhibition of endotrophin, a cleavage product of collagen VI, confers cisplatin sensitivity to tumours. EMBO Mol Med. 2013;5(6):935-948.

80. Varma RR, Hector SM, Clark K, Greco WR, Hawthorn L, Pendyala L. Gene expression profiling of a clonal isolate of oxaliplatin-resistant ovarian carcinoma cell line A2780/C10. Oncol Rep. 2005;14(4):925-932.

81. Fiorillo M, Sanchez-Alvarez R, Sotgia F, Lisanti MP. The ER-alpha mutation Y537S confers Tamoxifen-resistance via enhanced mitochondrial metabolism, glycolysis and Rho-GDI/ PTEN signaling: implicating TIGAR in somatic resistance to endocrine therapy. Aging (Albany NY). 2018;10(12):4000-4023. doi:10.18632/aging.101690

82. Ge C, Wu M, Chen G, Yu G, Ji D, Wang S. Identification of molecular characteristics induced by radiotherapy in rectal cancer based on microarray data. Oncol Lett. 2017;13(4):2777-2783. doi:10.3892/ol.2017.5750

83. Ge W, Hu H, Cai W, et al. High-risk Stage III colon cancer patients identified by a novel five-gene mutational signature are characterized by upregulation of IL-23A and gut bacterial translocation of the tumor microenvironment. Int $J$ Cancer. 2019;146:2027.

84. Yu J, Wu WK, Li X, et al. Novel recurrently mutated genes and a prognostic mutation signature in colorectal cancer. Gut. 2015;64 (4):636-645. doi:10.1136/gutjnl-2013-306620

85. Moller E, Mandahl N, Mertens F, Panagopoulos I. Molecular identification of COL6A3-CSF1 fusion transcripts in tenosynovial giant cell tumors. Genes Chromosomes Cancer. 2008;47 (1):21-25. doi:10.1002/gcc.20501

86. West RB, Rubin BP, Miller MA, et al. A landscape effect in tenosynovial giant-cell tumor from activation of CSF1 expression by a translocation in a minority of tumor cells. Proc Natl Acad Sci U S A. 2006;103(3):690-695. doi:10.1073/pnas.0507321103

87. Ho J, Peters T, Dickson BC, et al. Detection of CSF1 rearrangements deleting the $3^{\prime}$ UTR in tenosynovial giant cell tumors. Genes Chromosomes Cancer. 2020;59(2):96-105. doi:10.1002/ gcc. 22807

88. Willumsen N, Bager C, Karsdal MA. Matrix metalloprotease generated fragments of type VI collagen have serum biomarker potential in cancer - a proof of concept study. Transl Oncol. 2019;12(5):693-698. doi:10.1016/j.tranon.2019.02.004

89. Martianov I, Cler E, Duluc I, et al. TAF4 inactivation reveals the 3 dimensional growth promoting activities of collagen 6A3. PLoS One. 2014;9(2):e87365. doi:10.1371/journal.pone.0087365

90. Gadd S, Huff V, Walz AL, et al. A children's oncology group and TARGET initiative exploring the genetic landscape of WILMS tumor. Nat Genet. 2017;49(10):1487-1494. doi:10.10 38/ng.3940

91. Sun S, Henriksen K, Karsdal MA, et al. Collagen Type III and VI Turnover in Response to Long-Term Immobilization. PLoS One. 2015;10(12):e0144525. doi:10.1371/journal.pone.0144525 
92. Juhl P, Bay-Jensen AC, Karsdal M, Siebuhr AS, Franchimont N, Chavez J. Serum biomarkers of collagen turnover as potential diagnostic tools in diffuse systemic sclerosis: a cross-sectional study. PLoS One. 2018;13(12):e0207324. doi:10.1371/journal.pone.0207324

93. Rasmussen DGK, Hansen TW, von Scholten BJ, et al. Higher collagen vi formation is associated with all-cause mortality in patients with type 2 diabetes and microalbuminuria. Diabetes Care. 2018;41(7):1493-1500. doi:10.2337/dc17-2392

94. Karsdal MA, Henriksen K, Genovese F, et al. Serum endotrophin identifies optimal responders to PPARgamma agonists in type 2 diabetes. Diabetologia. 2017;60(1):50-59. doi:10.1007/s00125-0164094-1

95. Stolz D, Leeming DJ, Kristensen JHE, et al. Systemic biomarkers of collagen and elastin turnover are associated with clinically relevant outcomes in COPD. Chest. 2017;151(1):47-59. doi:10.1016/j.chest.2016.08.1440

96. Bihlet AR, Karsdal MA, Sand JM, et al. Biomarkers of extracellular matrix turnover are associated with emphysema and eosinophilic-bronchitis in COPD. Respir Res. 2017;18(1):22. doi:10.1186/s12931-017-0509-x
97. Sand JM, Martinez G, Midjord AK, Karsdal MA, Leeming DJ, Lange P. Characterization of serological neo-epitope biomarkers reflecting collagen remodeling in clinically stable chronic obstructive pulmonary disease. Clin Biochem. 2016;49 (15):1144-1151. doi:10.1016/j.clinbiochem.2016.09.003

98. Sand JM, Knox AJ, Lange P, et al. Accelerated extracellular matrix turnover during exacerbations of COPD. Respir Res. 2015;16(1):69. doi:10.1186/s12931-015-0225-3

99. Kehlet SN, Høye A, Boisen MK, et al. Prognostic evaluation of a new class of liquid biopsy biomarkers in patients with metastatic colorectal cancer: using the tumor microenvironment as a source of protein biomarkers. 2018;36(15 suppl):3588.

100. Cescon M, Gattazzo F, Chen P, Bonaldo P. Collagen VI at a glance. J Cell Sci. 2015;128(19):3525-3531. doi:10.1242/jcs.16 9748

101. Furthmayr H, Wiedemann H, Timpl R, Odermatt E, Engel J. Electronmicroscopical approach to a structural model of intima collagen. Biochem J. 1983;211(2):303-311. doi:10.1042/bj2110303

\section{Publish your work in this journal}

OncoTargets and Therapy is an international, peer-reviewed, open access journal focusing on the pathological basis of all cancers, potential targets for therapy and treatment protocols employed to improve the management of cancer patients. The journal also focuses on the impact of management programs and new therapeutic agents and protocols on patient perspectives such as quality of life, adherence and satisfaction. The manuscript management system is completely online and includes a very quick and fair peer-review system, which is all easy to use. Visit http://www.dovepress.com/ testimonials.php to read real quotes from published authors. 